\title{
Effects of different frequencies of transcutaneous electrical nerve stimulation on venous vascular reactivity
}

\author{
O.S. Franco ${ }^{1}$, F.S. Paulitsch ${ }^{1}$, A.P.C. Pereira ${ }^{1}$, A.O. Teixeira ${ }^{1}$, C.N. Martins ${ }^{2}$, A.M.V. Silva ${ }^{3}$, \\ R.D.M. Plentz ${ }^{4}$, M.C. Irigoyen ${ }^{5}$ and L.U. Signori ${ }^{1,2,3}$ \\ ${ }^{1}$ Programa de Pós-Graduação em Ciências da Saúde, Faculdade de Medicina, Universidade Federal do Rio Grande, \\ Rio Grande, RS, Brasil \\ ${ }^{2}$ Programa de Pós-Graduação em Fisiologia Animal Comparada, Instituto de Ciências Biológicas, \\ Universidade Federal do Rio Grande, Rio Grande, RS, Brasil \\ ${ }^{3}$ Departamento de Fisioterapia e Reabilitação, Universidade Federal de Santa Maria, Santa Maria, RS, Brasil \\ ${ }^{4}$ Programa de Pós-Graduação em Ciências da Saúde, Programa de Pós-Graduação em Ciências da Reabilitação, \\ Universidade Federal de Ciências da Saúde de Porto Alegre, Porto Alegre, RS, Brasil \\ ${ }^{5}$ Unidade de Hipertensão, Instituto do Coração, Faculdade de Medicina, Universidade de São Paulo, São Paulo, SP, Brasil
}

\begin{abstract}
Transcutaneous electrical nerve stimulation (TENS) is a type of therapy used primarily for analgesia, but also presents changes in the cardiovascular system responses; its effects are dependent upon application parameters. Alterations to the cardiovascular system suggest that TENS may modify venous vascular response. The objective of this study was to evaluate the effects of TENS at different frequencies $(10$ and $100 \mathrm{~Hz})$ on venous vascular reactivity in healthy subjects. Twenty-nine healthy male volunteers were randomized into three groups: placebo $(n=10)$, low-frequency TENS $(10 \mathrm{~Hz}, n=9)$ and highfrequency TENS $(100 \mathrm{~Hz}, \mathrm{n}=10)$. TENS was applied for $30 \mathrm{~min}$ in the nervous plexus trajectory from the superior member (from cervical to dorsal region of the fist) at low $(10 \mathrm{~Hz} / 200 \mu \mathrm{s})$ and high frequency $(100 \mathrm{~Hz} / 200 \mu \mathrm{s})$ with its intensity adjusted below the motor threshold and intensified every $5 \mathrm{~min}$, intending to avoid accommodation. Venous vascular reactivity in response to phenylephrine, acetylcholine (endothelium-dependent) and sodium nitroprusside (endothelium-independent) was assessed by the dorsal hand vein technique. The phenylephrine effective dose to achieve $70 \%$ vasoconstriction was reduced $53 \%(\mathrm{P}<0.01)$ using low-frequency TENS $(10 \mathrm{~Hz})$, while in high-frequency stimulation $(100 \mathrm{~Hz})$, a $47 \%$ increased dose was needed $(P<0.01)$. The endothelium-dependent (acetylcholine) and independent (sodium nitroprusside) responses were not modified by TENS, which modifies venous responsiveness, and increases the low-frequency sensitivity of $\alpha 1$-adrenergic receptors and shows high-frequency opposite effects. These changes represent an important vascular effect caused by TENS with implications for hemodynamics, inflammation and analgesia.
\end{abstract}

Key words: Electric stimulation therapy; Vascular endothelium; Alpha-1 adrenergic receptors; Mechanical pain

\section{Introduction}

Transcutaneous electric nervous stimulation (TENS) has been widely used as a tool for treatment of acute and chronic pain. However, this therapeutic modality modifies the cardiovascular system responses, causing vasodilation $(1,2)$, increasing blood flow $(1,3-5)$, and decreasing peripheral vascular resistance (6-8), heart rate (9) and systemic arterial blood pressure $(2,8,9)$, all of which are associated with modulating the autonomic balance $(2,10)$. Therefore, some studies have focused on the application of the mentioned therapeutic tools in the treatment of other clinical conditions, such as those involving the alteration of systemic arterial pressure, as observed for hypertension $(2,11-13)$ and diabetes $(14,15)$.

TENS parameters are variable, according to intensity, frequency, pulse duration, positioning of the electrodes and application time $(16,17)$. Regarding the cardiovascular system, the pulse frequency appears to present different hemodynamic responses, usually applied at low $(<10 \mathrm{~Hz})$ or high $(>50 \mathrm{~Hz})$ frequencies (17). The application of acute TENS at low frequencies $(2$ and $4 \mathrm{~Hz}$ ) produced a 
local increase of muscular (5) and cutaneous (4) blood flow. On the other hand, at high frequencies (80 and $110 \mathrm{~Hz}$ ), these alterations were not noticed. However, high frequency $(80 \mathrm{~Hz})$ promoted vasodilatation, reduced systemic arterial blood pressure, and improved sympathetic-vagal balance during exercise (2). Also, when applied in the precordial region $(70$ and $150 \mathrm{~Hz}$ ), it reduced serum levels of catecholamines in patients with angina pectoris $(3,7)$.

Alterations caused by TENS on the cardiovascular system (1-10), especially the changes to the autonomic nervous system $(2,10)$, possibly interact with the layer of endothelial cells, because these share a functional antagonism with sympathetic nervous system efferents in maintaining blood vessel tone (18). The endothelium constitutes a dynamic tissue, which is interposed between the blood and the smooth muscle layer of blood vessels, and is responsive to physical and chemical stimuli, with consequent synthesis and/or release of regulatory substances that affect the vascular tonus, its growth, and platelet and leukocyte aggregation. In addition, it modulates the interaction among these cells $(19,20)$.

The effects of TENS on venous vascular reactivity and endothelium venous function have not yet been investigated, and the changes in the cardiovascular system are dependent on the application parameters $(4,16,17)$. Based on the information described above, we hypothesized that different application parameters of this electrical stimulation modify these variables of the cardiovascular system. The aim of this study was to evaluate the effects of different frequencies (10 and $100 \mathrm{~Hz}$ ) of TENS on venous vascular reactivity in healthy volunteers.

\section{Material and Methods}

\section{Setting and participants}

The study was approved by the Health Research Ethics Committee at Universidade Federal do Rio Grande, Brazil (CEPAS-FURG, No. 78/2011), and all subjects provided written informed consent. The evaluations were carried out from December 2011 to December 2012 at Dr. Miguel Riet Corrêa Jr. University Hospital, Universidade Federal do Rio Grande (Rio Grande, RS, Brazil). The subjects who joined the study were between 20 and 35 years of age; presenting a body mass index $\left(\mathrm{kg} / \mathrm{m}^{2}\right)$ lower than 30 ; nonsmokers; with no symptoms of skeletal muscle disorders; with no previous diagnosis of rheumatic, cardiovascular, metabolic, neurological, oncological, immune, or hematological diseases; with no evidence of psychiatric and/or cognitive disorders; and were not using any type of medication. Volunteers presenting inflammatory response (C-reactive protein $>3 \mathrm{mg} / \mathrm{dL}$, fibrinogen $<200$ or $>400 \mathrm{mg} / \mathrm{dL}$ ) or leukocytosis $\left(11.000 \times 10^{3} / \mathrm{mm}^{3}\right)$ or who had consumed alcoholic beverages up to $24 \mathrm{~h}$ before the test were excluded.

\section{Study design}

The sample was composed of 30 volunteers (according to the sample calculation), randomized by a computer program (www.random.org). The information was sealed in a brown envelope, and the groups and evaluators were blinded to the type of intervention. The groups were divided into the placebo group $(n=10)$, the low-frequency TENS group (10 Hz, $n=9$ ), and the high-frequency TENS group $(100 \mathrm{~Hz}, \mathrm{n}=10)$. After data collection, one volunteer was excluded due to evidence of leukocytosis and high Creactive protein levels. A flowchart of the volunteers is presented in Figure 1. Venous endothelial function was

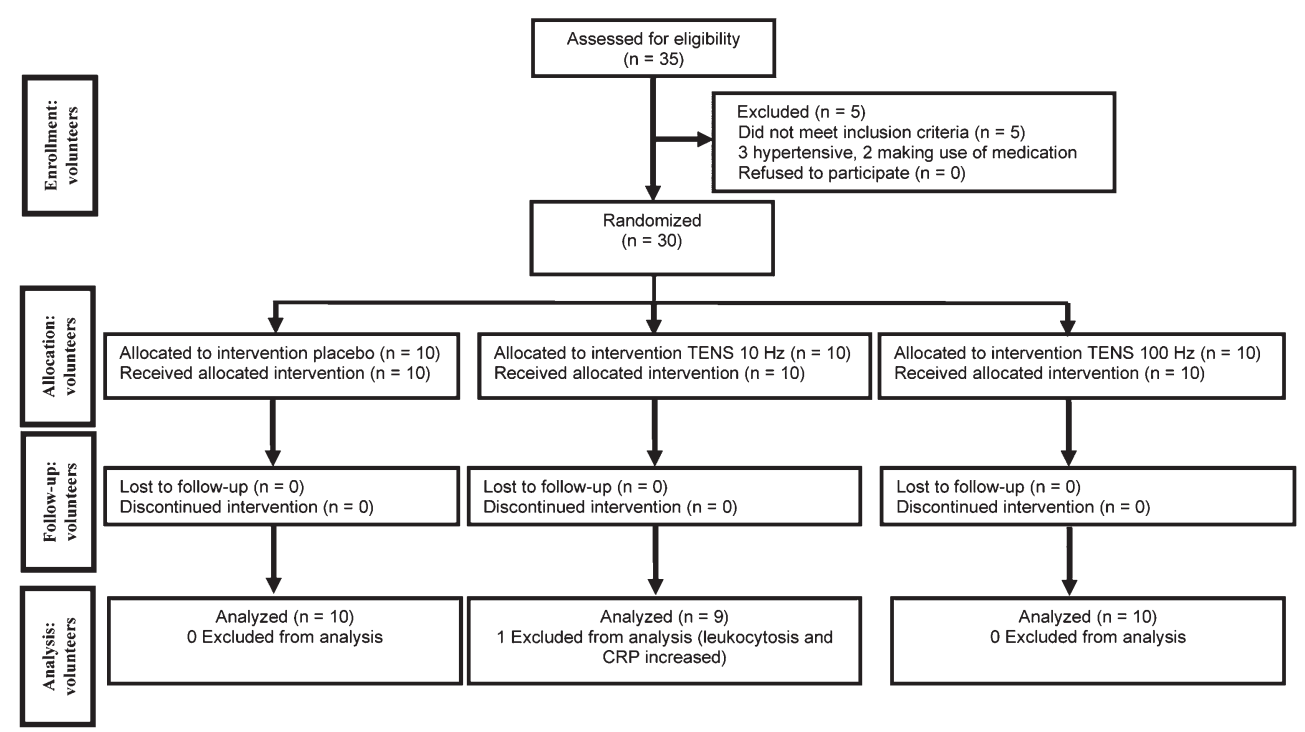

Figure 1. Flowchart of the volunteers in the study. 


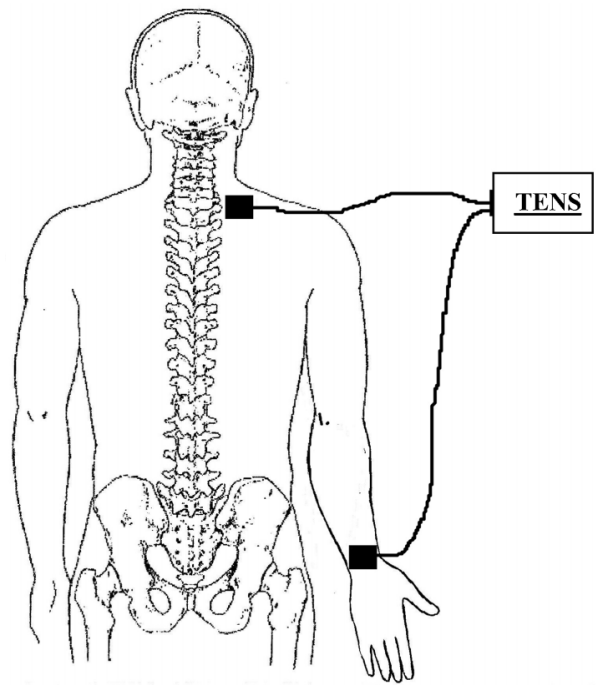

Figure 2. Location of electrodes.

evaluated before and immediately after the application of TENS. To prevent postprandial metabolic interference, volunteers underwent a 12-h fasting period $(21,22)$ and remained in this condition during the experimental protocol.

\section{Interventions}

During the application of the protocol, the volunteers were lying comfortably in a supine position, with a head elevation of $30^{\circ}$, resting their knees and elbows over the bed. The spots where the electrodes were placed were previously cleaned with $70 \%$ alcohol. TENS equipment (Quark, model Nemesys 941, Brazil), waveform biphasic symmetric, was applied on the nervous plexus trajectory from the superior member. Autoadhesive electrodes $(5 \times 5 \mathrm{~cm}$ area) were used and placed distally in the dorsal region of the wrist and in the proximal region of the cervicothoracic region (between $\mathrm{C} 4$ and T1), as shown in Figure 2. TENS was applied for $30 \mathrm{~min}$ at a low (TENS, $10 \mathrm{~Hz} / 200 \mu \mathrm{s}$ ) or high (TENS, $100 \mathrm{~Hz} / 200 \mu \mathrm{s}$ ) frequency. The intensity of the current was adjusted, initially and after every $5 \mathrm{~min}$, under the motor threshold. The aforementioned procedures were repeated in the placebo group with the equipment turned off. The equipment was standardized before and after data collection.

\section{Measurements}

Venous endothelial function was assessed in all volunteers with the dorsal hand vein technique. This method was previously described by Aellig (21). Briefly, a 23-gauge butterfly needle was inserted into a suitable vein on the back of the hand, and a continuous infusion of physiological saline $(0.3 \mathrm{~mL} / \mathrm{min})$ was started. A tripod holding a linear variable differential transformer (LVDT; Shaevitz Engineering, USA) was mounted on the hand with the central aperture of the LVDT that contained a movable metallic core at a distance of $10 \mathrm{~mm}$ downstream from the tip of the needle. The signal output of the LVDT, which is linearly proportional to the vertical movement of the core, provided a measurement of the vein diameter. Readings were taken at a congestive pressure of $40 \mathrm{mmHg}$ by inflating a blood pressure cuff placed on the upper portion of the arm being studied. The diameter of the vein during saline infusion with the cuff inflated was defined as 100\% relaxation. Afterward, the vein was preconstricted, by infusing increasing doses ( $7 \mathrm{~min}$ each) of the $\alpha 1$-adrenergic selective agonist phenylephrine $(37-25,000 \mathrm{ng} / \mathrm{mL})$, until the dose that produced approximately $70 \%$ constriction of the vein $\left(E D_{70}\right)$ was found. This degree of preconstriction was defined as $0 \%$ venodilation. Endothelium-dependent venodilation was assessed with incremental infusions ( 6 doses for $3 \mathrm{~min}$ each dose) of acetylcholine $(12-12,000 \mathrm{ng} / \mathrm{mL})$. Endothelium-independent (3 doses) vasodilation was assessed with sodium nitroprusside (156-3,125 ng/mL). Both were calculated as the percentage range between 100 and $0 \%$ venodilation. The individual effects were analyzed as the percentage of maximum venodilation $(21,22-25)$. Drugs were infused with a Harvard infusion pump (Harvard Apparatus Inc., USA). Blood pressure and heart rate were monitored in the contralateral arm with a sphygmomanometer. Ambient temperature was kept constant $\left(23^{\circ}-25^{\circ} \mathrm{C}\right)$.

Cholesterol, triglycerides, high-density lipoproteins, glucose, and urea were measured using Labtest kits (Labtest Diagnóstica SA, Brazil) and analyzed using Lab Max $240^{\circledR}$ (Japan) equipment. Low-density lipoproteins were calculated by Friedewald's formula. Fibrinogen was analyzed by Start (Diagnostica Stago, France) equipment using a Labtest kit. Ultrasensitive C-reactive protein was evaluated by nephelometry (nephelometer model IMMAGE using laboratory reagent CCRP, Beckman Coulter, USA). Hemogram blood tests (erythrogram and leukogram) were automatically processed using $A B X$ kits (Horiba Diagnóstica, Brazil) and also by microscopy. Glucose levels were measured by the Trinder assay (calorimetry) in Lab Max $240^{\mathbb{R}}$ equipment. Insulin was assessed by chemiluminescence using Immulite ${ }^{\mathbb{R}}$ DPC equipment (Diagnostic Products Corporation, USA). Glycosylated hemoglobin was determined by an enzymatic method using Lab Max $240^{\circledR}$ equipment.

\section{Sample calculation}

We estimated that a sample size of 9 individuals in each group would have a power of $80 \%$ to detect a $60 \%$ difference between means (phenylephrine dose) of $70 \%$ constriction of the vein $\left(E D_{70}\right)$ with $40 \%$ standard deviation, for $\alpha=0.05$.

\section{Data analysis}

All continuous variables were tested for normal distribution with the Kolmogorov-Smirnov test. Continuous variables are reported as means \pm SD if normally distributed; 
Table 1. Clinical and metabolic characteristics of the studied subjects.

\begin{tabular}{|c|c|c|c|}
\hline Characteristic & Placebo $(n=10)$ & TENS $10 \mathrm{~Hz}(\mathrm{n}=9)$ & TENS $100 \mathrm{~Hz}(=10)$ \\
\hline Age (years) & $29.5 \pm 4.9$ & $26.7 \pm 5.7$ & $28.5 \pm 5.6$ \\
\hline BMI $\left(\mathrm{kg} / \mathrm{m}^{2}\right)$ & $26.7 \pm 2.5$ & $25.7 \pm 2.2$ & $25.6 \pm 2.2$ \\
\hline Waist/hip & $0.84 \pm 0.1$ & $0.87 \pm 0.1$ & $0.84 \pm 0.1$ \\
\hline $\mathrm{SBP}(\mathrm{mmHg})$ & $119.6 \pm 4.0$ & $119.1 \pm 8.1$ & $116.2 \pm 7.4$ \\
\hline $\mathrm{DBP}(\mathrm{mmHg})$ & $78.9 \pm 2.1$ & $80.6 \pm 3.7$ & $77.7 \pm 3.6$ \\
\hline Hematocrit (mL/\%) & $47.4 \pm 3.9$ & $48.1 \pm 3.1$ & $47.6 \pm 3.2$ \\
\hline Erythrocytes $\left(\times 10^{5} / \mathrm{mm}^{3}\right)$ & $49.2 \pm 0.4$ & $48.6 \pm 0.4$ & $51.2 \pm 0.4$ \\
\hline Hemoglobin $(\mathrm{g} / \mathrm{dL})$ & $14.7 \pm 1.1$ & $14.4 \pm 1.1$ & $14.9 \pm 1.0$ \\
\hline Leukocytes $\left(\times 10^{3} / \mathrm{mm}^{3}\right)$ & $6100 \pm 807$ & $5822 \pm 958$ & $6450 \pm 1420$ \\
\hline Platelets $\left(\times 10^{3} / \mathrm{mm}^{3}\right)$ & $268 \pm 39$ & $302 \pm 63$ & $284 \pm 64$ \\
\hline Cholesterol (mg/dL) & $161 \pm 34$ & $155 \pm 35$ & $152 \pm 35$ \\
\hline Triglycerides (mg/dL) & $100 \pm 60$ & $92 \pm 74$ & $94 \pm 52$ \\
\hline $\mathrm{HDL}-\mathrm{C}(\mathrm{mg} / \mathrm{dL})$ & $28 \pm 5$ & $31 \pm 9$ & $31 \pm 5$ \\
\hline LDL-C (mg/dL) & $113 \pm 28$ & $106 \pm 25$ & $102 \pm 33$ \\
\hline Plasma glucose (mg/dL) & $77 \pm 5$ & $78 \pm 4$ & $74 \pm 7$ \\
\hline Insulin $(\mu \mathrm{U} / \mathrm{mL})$ & $5.6 \pm 5$ & $5.6 \pm 5$ & $4.7 \pm 4$ \\
\hline $\mathrm{HbA}_{1 \mathrm{c}}(\%)$ & $5.2 \pm 0.9$ & $5.1 \pm 0.8$ & $5.1 \pm 0.9$ \\
\hline Fibrinogen (mg/dL) & $281 \pm 66$ & $258 \pm 53$ & $269 \pm 65$ \\
\hline CRP (mg/dL) & $1.7 \pm 0.9$ & $1.4 \pm 1.0$ & $1.7 \pm 1.0$ \\
\hline
\end{tabular}

Data are reported as means \pm SD. BMI: body mass index; SBP: systolic blood pressure; DBP: diastolic blood pressure; HDL-C: high-density lipoprotein cholesterol; LDL-C: low-density lipoprotein cholesterol; $\mathrm{HbA}_{1 \mathrm{c}}$ : glycated hemoglobin; CRP: C-reactive protein. P $>0.05$ (ANOVA)

otherwise, they are reported as median with 25th and 75th percentiles. Variations between drug dose (dose after minus dose before) are reported as mean differences and 95\% confidence intervals $(95 \% \mathrm{Cl})$. Variables that did not have a Gaussian distribution were log transformed before further analysis $\left(\log _{10}\right)$. Differences between the characteristics of the groups were tested with one-way analysis of variance (ANOVA). For data obtained on two occasions, a two-way repeated-measure ANOVA followed by the Bonferroni post hoc test was applied. $\mathrm{P}<0.05$ was considered to be statistically significant.

\section{Results}

The characteristics of the volunteers are shown in Table 1. The groups did not present differences regarding physical or biochemical variables. The 29 volunteers were normotensive, eutrophic, and normoglycemic, with no evidence of inflammatory processes and presenting all of the remaining blood biochemical variables under normal conditions.

Venous endothelial function data are reported in Table 2. Venoconstriction percentages $\left(E D_{70}\right)$ in response to phenylephrine and maximum venodilation (Emax) responses (endothelium-dependent, in response to acetylcholine, and endothelium-independent, in response to sodium nitroprusside) were not modified in response to TENS. Phenylephrine, acetylcholine, and nitroprusside doses were similar among groups before TENS application. The necessary phenylephrine dose to reach $E D_{70}$ after TENS application remained the same in the placebo group. However, the application of TENS at low frequencies $(10 \mathrm{~Hz})$ decreased the phenylephrine dose to reach $E D_{70}$ by $53 \%(\mathrm{P}<0.01$, mean difference $-39.6 \mathrm{ng} / \mathrm{mL}, 95 \% \mathrm{Cl}=$ -57 to -21$)$. On the other hand, after high-frequency stimulus $(100 \mathrm{~Hz})$, a $47 \%$ higher phenylephrine dose was necessary $(P<0.01$, mean difference $90.0 \mathrm{ng} / \mathrm{mL}$, $95 \% \mathrm{Cl}=19-160$ ) to reach this effect (group: $P=0.011$, interaction: $P<0.001$; data are reported as $\log _{10}$ in Figure 3 ). TENS did not change the doses of acetylcholine and sodium nitroprusside required to reach Emax. Arterial systolic and diastolic pressures were not modified after the application of different frequencies of TENS (data not shown).

\section{Discussion}

Our data showed that TENS modified the venous response and different stimulation frequencies increase or diminish the sensitivity of $\alpha 1$-adrenergic receptors. Low frequencies $(10 \mathrm{~Hz})$ increased and high frequencies $(100 \mathrm{~Hz})$ decreased the sensitivity of these receptors, demonstrating that different stimulus frequencies promote opposite effects on these receptors, depending on TENS application. Regarding the cardiovascular system, the $\alpha 1$ adrenergic receptor alters vasomotricity, modulating peripheral vascular resistance by venoconstriction, and cooperating with systemic arterial blood pressure adjustments by venous return, in response to sympathetic nervous system stimulation by catecholamines $(26,27)$. Noradrenalin (relatively nonselective) and adrenalin (lightly 
Table 2. Venoconstriction (phenylephrine) and endothelium-dependent (acetylcholine) and endothelium-independent (sodium nitroprusside) venodilation in percentage and drug concentrations.

\begin{tabular}{|c|c|c|c|c|c|}
\hline Response to TENS & Before & After & Group & Time & Interaction \\
\hline \multicolumn{6}{|l|}{ Percentage } \\
\hline \multicolumn{6}{|c|}{ Phenylephrine $\mathrm{ED}_{70 \%}$} \\
\hline Placebo & $76 \pm 8$ & $73 \pm 5$ & 0.770 & 0.180 & 0.951 \\
\hline $10 \mathrm{~Hz}$ & $74 \pm 9$ & $71 \pm 9$ & & & \\
\hline $100 \mathrm{~Hz}$ & $75 \pm 9$ & $73 \pm 6$ & & & \\
\hline \multicolumn{6}{|c|}{ Acetylcholine \%Emax } \\
\hline Placebo & $82 \pm 17$ & $83 \pm 10$ & 0.160 & 0.321 & 0.404 \\
\hline $10 \mathrm{~Hz}$ & $79 \pm 11$ & $92 \pm 20$ & & & \\
\hline $100 \mathrm{~Hz}$ & $81 \pm 22$ & $75 \pm 12$ & & & \\
\hline \multicolumn{6}{|c|}{ Sodium nitroprusside \%Emax } \\
\hline Placebo & $152 \pm 27$ & $147 \pm 26$ & 0.807 & 0.993 & 0.829 \\
\hline $10 \mathrm{~Hz}$ & $150 \pm 26$ & $153 \pm 35$ & & & \\
\hline $100 \mathrm{~Hz}$ & $152 \pm 28$ & $147 \pm 23$ & & & \\
\hline \multicolumn{6}{|c|}{ Drug concentration } \\
\hline \multicolumn{6}{|c|}{ Phenylephrine $\mathrm{ED}_{70 \%}(\mathrm{ng} / \mathrm{mL})$} \\
\hline Placebo & $75(75-262)$ & $75(75-262)$ & 0.011 & 0.928 & $<0.001$ \\
\hline $10 \mathrm{~Hz}$ & $75(75-75)$ & $38(38-75)^{*} \#$ & & & \\
\hline $100 \mathrm{~Hz}$ & $75(75-244)$ & $150(150-300)^{* \#+}$ & & & \\
\hline \multicolumn{6}{|c|}{ Acetylcholine \%Emax (ng/mL) } \\
\hline Placebo & $660(120-5100)$ & $660(120-2400)$ & 0.574 & 0.571 & 0.922 \\
\hline $10 \mathrm{~Hz}$ & $1200(120-2400)$ & $1200(120-2400)$ & & & \\
\hline $100 \mathrm{~Hz}$ & $2400(390-6000)$ & $1800(1200-5100)$ & & & \\
\hline \multicolumn{6}{|c|}{ Sodium nitroprusside Emax $(\mathrm{ng} / \mathrm{mL})$} \\
\hline Placebo & $1562(1562-1562)$ & $1562(1562-1562)$ & 0.762 & 0.940 & 0.235 \\
\hline $10 \mathrm{~Hz}$ & $1562(1562-1562)$ & $1562(1562-1562)$ & & & \\
\hline $100 \mathrm{~Hz}$ & $1562(976-1562)$ & $1562(976-1562)$ & & & \\
\hline
\end{tabular}

Data are reported as means $\pm S D$ if normal distribution, and median with 25th to 75 th percentile if not normal distribution. ${ }^{*}<0.05$, before vs after; ${ }^{\#} \mathrm{P}<0.05$, TENS vs placebo; ${ }^{+} \mathrm{P}<0.05$, TENS $10 \mathrm{~Hz}$ vs TENS $100 \mathrm{~Hz}$ (two-way ANOVA with repeated measures followed by the Bonferroni test).

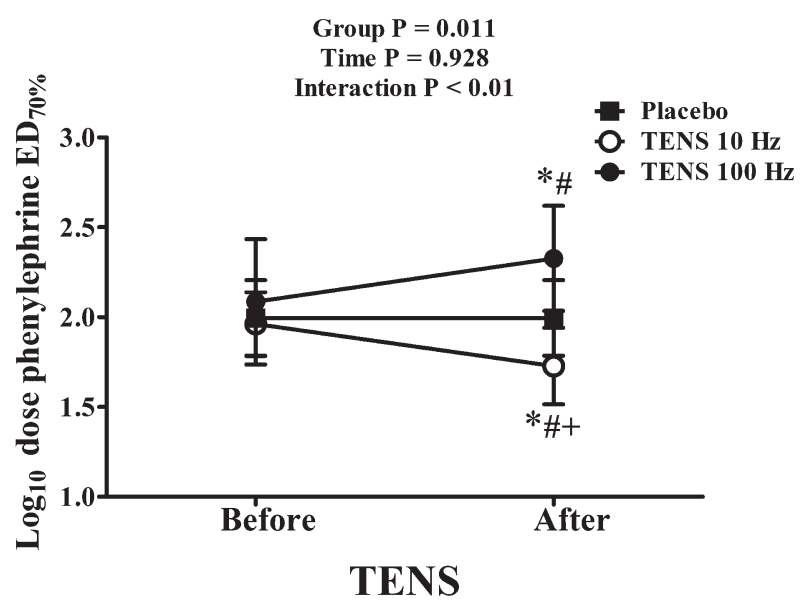

Figure 3. Phenylephrine dose required to reach $\mathrm{ED}_{70 \%}$ of venoconstriction. Data are reported as means $\pm S D$. ${ }^{*} P<0.05$, before vs after; ${ }^{\#} \mathrm{P}<0.05$, TENS vs placebo; ${ }^{+} \mathrm{P}<0.05$, TENS $10 \mathrm{~Hz}$ vs TENS $100 \mathrm{~Hz}$ (two-way ANOVA with repeated measures followed by the Bonferroni test). selective for $\alpha 2$-adrenoceptors) are the catecholamines acting on $\alpha 1$ - and $\alpha 2$-adrenoceptor peripherals interfering in blood circulation $(26,27)$, and the main sources are circulation and local release from postganglion sympathetic nerve fibers (28). The increase in the endogenous catecholamines is associated with modulation of pain and the innate immune response $(28,29)$.

$\alpha 1$-adrenergic receptor sensitivity changes in response to different frequencies of TENS application, which might be caused by variations in plasma concentrations of catecholamines or by direct effects on receptors. For patients presenting angina pectoris, TENS, when applied on the precordial region at high frequencies (150 and $70 \mathrm{~Hz}$ ), diminishes peripheral vascular resistance and arterial systolic pressure (7) by reducing serum levels of adrenalin $(3,7)$ and noradrenalin (7) and increasing coronary blood flow, suggesting that these alterations occur at the microcirculation level (3). Despite the levels of these neurotransmitters not being measured in the present study, the mentioned studies present a hypothesis for the effect found in our research, as catecholamines are the 
agonists of $\alpha 1$ - and $\alpha 2$-adrenergic receptors $(26,30)$ and were decreased after TENS application.

Another mechanism proposed for sensitivity alterations of $\alpha 1$-adrenergic receptors is the local activation of sympathetic postganglion fibers. Sherry et al. (8) have demonstrated that TENS at low frequencies promotes the circulatory alterations caused by the stimulation of sympathetic postganglion efferent fibers. TENS at low frequencies produced small and transitory increases in the blood flow and reduced the cutaneous temperature, suggesting that these responses were not evinced at high frequencies $(4,31)$. This increase in blood flow was also demonstrated in the skeletal musculature, but only for TENS at low frequencies (5). Miller et al. (1) have shown that the increase in blood flow and reduction of peripheral vascular resistance are similar to voluntary muscle contractions, as TENS at low frequencies has increased the persistence of this effect. This method of TENS application favors skeletal muscle contraction $(1,5)$, which leads to an increase in blood flow due to arterial vasodilation and local venoconstriction (26). Therefore, this state of venous preconstriction would promote a greater sensitivity of the $\alpha 1$-adrenergic receptors found in our study after the application of low-frequency TENS.

The results of clinical effectiveness from different TENS frequencies on the hemodynamic response are controversial. For healthy subjects, low-frequency TENS reduced sympathetic and increased parasympathetic modulation; however, at high frequencies, these results were the opposite (10). In this regard, the chronic application of lowfrequency TENS reduced arterial systolic and diastolic pressure in hypertensive patients $(11,12)$. However, recent studies have demonstrated that, at low frequency, TENS did not modify the values of systemic arterial pressure in normotensive (32) and hypertensive volunteers (13). On the other hand, high-frequency TENS decreased heart rate, systolic arterial pressure, and the double product in healthy volunteers (9). For hypertensive patients, this method of application promoted a decrease in systemic arterial pressure and metaboreflex and vasoconstriction responses, leading to an improvement of the sympathetic-vagal balance during exercise (2). Our results suggest that the hemodynamic alterations produced by different frequencies of TENS present a biphasic sympathetic response of $\alpha 1$-adrenergic receptors. Moreover, it should be emphasized that the different hemodynamic responses are related to other parameters (intensity, frequency, pulse duration, electrode positioning, and application time) of TENS application $(16,17)$, as well as to different types of populations studied. Therefore, the results of this study, regarding frequency, differ from each other and must be analyzed according to the context in which they were carried out.

Borderline hypertensive patients and young descendants of hypertensive persons have presented lower venous compliance, partly due to the increase in venoconstriction mediated by $\alpha 1$-adrenergic receptors (33).
TENS peripherally applied at high frequencies reduces the sensitivity of these receptors and increases venous compliance, which favors the reduction of systemic arterial pressure, for this clinical condition, and allows, therefore, the perception of a potential nonpharmacological therapy, especially for patients presenting refractory hypertension and/or hypertensive crisis. In the present study, it should be highlighted that no modifications in systemic arterial pressure were observed and, although the study was not designed to analyze this closure, the authors believe that this fact is due to the normotensive characteristic of the volunteers and also due to the small area of TENS application (superior member).

To understand the analgesic and anti-inflammatory implications caused by the changes in $\alpha 1$-adrenergic receptor sensitivity in response to TENS application, it should be emphasized that the sympathetic nervous system is an important regulatory mechanism for the innate immune response $(28,29)$. King et al. (30) have demonstrated in an experimental study that TENS at low and high frequencies modifies the sensitivity of peripheral $\alpha 2$-adrenergic receptors and that this mechanism contributes to the analgesia efficiency mediated by this method. On the other hand, $\alpha 1$-adrenergic receptors seem to present postinflammatory effects as a response to the immune system, especially chronic inflammatory effects (34). Studies involving human cell cultures have shown that the expression of these receptors in monocytes and macrophages increases interleukin (IL)-1 production (31). The same occurs in fibroblasts and cardiomyocytes, in which stimulation of the mentioned receptors promotes the expression and production of IL- 6 (34). Regarding both situations, p38 mitogen-activated protein kinase and nuclear factor- $\mathrm{KB}$ pathways are involved $(29,34)$. These cells directly interact with the vascular endothelium (19), and this might be one mechanism by which alteration in the function of $\alpha 1$-adrenergic receptors induced by TENS can interfere in the inflammatory response. The absence of plasma catecholamine measures and the local application of TENS are the limitations of the present study.

In conclusion, TENS modifies venous responsiveness verified by changed responses of venoconstriction and $\alpha 1$-adrenergic receptors, considering that low frequency increases and high frequency reduces the sensitivity of these receptors. These data present a new action mechanism of TENS on the cardiovascular system that may have implications on the hemodynamic and inflammatory responses in healthy or diseased subjects.

\section{Acknowledgments}

We would like to thank Laboratório de Análises Clínicas, Associação de Caridade Santa Casa de Rio Grande, and Instituto de Ciências Biológicas, Universidade Federal do Rio Grande, for their collaboration with data processing and analysis. 


\section{References}

1. Miller BF, Gruben KG, Morgan BJ. Circulatory responses to voluntary and electrically induced muscle contractions in humans. Phys Ther 2000; 80: 53-60.

2. Vieira PJ, Ribeiro JP, Cipriano G Jr, Umpierre D, Cahalin LP, Moraes RS, et al. Effect of transcutaneous electrical nerve stimulation on muscle metaboreflex in healthy young and older subjects. Eur J Appl Physiol 2012; 112: 13271334, doi: 10.1007/s00421-011-2084-z.

3. Chauhan A, Mullins PA, Thuraisingham SI, Taylor G, Petch MC, Schofield PM. Effect of transcutaneous electrical nerve stimulation on coronary blood flow. Circulation 1994; 89: 694-702, doi: 10.1161/01.CIR.89.2.694.

4. Cramp AF, Gilsenan C, Lowe AS, Walsh DM. The effect of high- and low-frequency transcutaneous electrical nerve stimulation upon cutaneous blood flow and skin temperature in healthy subjects. Clin Physiol 2000; 20: 150-157, doi: 10.1046/j.1365-2281.2000.00240.x.

5. Sandberg ML, Sandberg MK, Dahl J. Blood flow changes in the trapezius muscle and overlying skin following transcutaneous electrical nerve stimulation. Phys Ther 2007; 87: 1047-1055, doi: 10.2522/ptj.20060178.

6. Mannheimer C, Carlsson CA, Vedin A, Wilhelmsson C. Transcutaneous electrical nerve stimulation (TENS) in angina pectoris. Pain 1986; 26: 291-300, doi: 10.1016/03043959(86)90058-8.

7. Mannheimer $\mathrm{C}$, Emanuelsson $\mathrm{H}$, Waagstein $\mathrm{F}$. The effect of transcutaneous electrical nerve stimulation (TENS) on catecholamine metabolism during pacing-induced angina pectoris and the influence of naloxone. Pain 1990; 41: 2734, doi: 10.1016/0304-3959(90)91105-R.

8. Sherry JE, Oehrlein KM, Hegge KS, Morgan BJ. Effect of burst-mode transcutaneous electrical nerve stimulation on peripheral vascular resistance. Phys Ther 2001; 81: 11831191.

9. Nitz J. Haemodynamic response to TENS applied to the upper thoracic nerve roots in normal subjects. Hong Kong Physiother J 2003; 21: 58-61, doi: 10.1016/S1013-7025(09) 70041-7.

10. Stein C, Dal Lago P, Ferreira JB, Casali KR, Plentz RD. Transcutaneous electrical nerve stimulation at different frequencies on heart rate variability in healthy subjects. Auton Neurosci 2011; 165: 205-208, doi: 10.1016/j.autneu. 2011.07.003.

11. Kaada B, Flatheim E, Woie L. Low-frequency transcutaneous nerve stimulation in mild/moderate hypertension. Clin Physiol 1991; 11: 161-168, doi: 10.1111/j.1475-097X.1991. tb00109.x.

12. Jacobsson F, Himmelmann A, Bergbrant A, Svensson A, Mannheimer $C$. The effect of transcutaneous electric nerve stimulation in patients with therapy-resistant hypertension. J Hum Hypertens 2000; 14: 795-798, doi: 10.1038/sj.jhh. 1001112.

13. Silverdal J, Mourtzinis G, Stener-Victorin E, Mannheimer C, Manhem K. Antihypertensive effect of low-frequency transcutaneous electrical nerve stimulation (TENS) in comparison with drug treatment. Blood Press 2012; 21: 306-310, doi: 10.3109/08037051.2012.680737.

14. Meng H, Hao JD, Wang HC, Zhao JY, Zhao CL, Zhai X. [Effects of different frequencies of electroacupuncture on blood glucose level in impaired glucose tolerance patients] Zhen Ci Yan Jiu 2011; 36: 220-223.

15. Khan MU. Is there a role for TENS application in the control of diabetes mellitus in insulin-dependent patients? Singapore Med J 2012; 53: e249-e250.

16. Gopalkrishnan P, Sluka KA. Effect of varying frequency, intensity, and pulse duration of transcutaneous electrical nerve stimulation on primary hyperalgesia in inflamed rats. Arch Phys Med Rehabil 2000; 81: 984-990, doi: 10.1053/ apmr.2000.5576.

17. Chesterton LS, Foster NE, Wright CC, Baxter GD, Barlas P. Effects of TENS frequency, intensity and stimulation site parameter manipulation on pressure pain thresholds in healthy human subjects. Pain 2003; 106: 73-80, doi: 10.1016/S0304-3959(03)00292-6.

18. Harris KF, Matthews KA. Interactions between autonomic nervous system activity and endothelial function: a model for the development of cardiovascular disease. Psychosom Med 2004; 66: 153-164, doi: 10.1097/01.psy.0000116719. 95524.e2.

19. Trepels $\mathrm{T}$, Zeiher AM, Fichtlscherer $\mathrm{S}$. The endothelium and inflammation. Endothelium 2006; 13: 423-429, doi: 10.1080/ 10623320601061862.

20. Higashi Y, Noma K, Yoshizumi M, Kihara Y. Endothelial function and oxidative stress in cardiovascular diseases. Circ J 2009; 73: 411-418, doi: 10.1253/circj.CJ-08-1102.

21. Aellig $\mathrm{WH}$. A new technique for recording compliance of human hand veins. Br J Clin Pharmacol 1981; 11: 237-243, doi: 10.1111/j.1365-2125.1981.tb00527.x.

22. Signori LU, da Silva AM, Plentz RD, Moreno H Jr, Irigoyen MC, Schaan BD. Reversal of postprandial endothelial dysfunction by cyclooxygenase inhibition in healthy volunteers. J Cardiovasc Pharmacol 2009; 54: 90-93, doi: 10.1097/FJC.0b013e3181abc26f.

23. Signori LU, Vargas da Silva AM, Della Mea Plentz R, Geloneze B, Moreno H Jr, Bello-Klein A, et al. Reduced venous endothelial responsiveness after oral lipid overload in healthy volunteers. Metabolism 2008; 57: 103-109, doi: 10.1016/j.metabol.2007.08.012.

24. Silva AM, Signori LU, Plentz RD, Moreno Jr H, Barros E, Bello-Klein $A$, et al. Hemodialysis improves endothelial venous function in end-stage renal disease. Braz J Med Biol Res 2008; 41: 482-488, doi: 10.1590/S0100-879X20080006 00008.

25. Signori LU, Quadros AS, Sbruzzi G, Dipp T, Lopes RD, Schaan BD. Endothelial function in patients with slow coronary flow and normal coronary angiography. Clinics 2012; 67: 677-680, doi: 10.6061/clinics/2012(06)22.

26. Ruffolo RR Jr. Distribution and function of peripheral alphaadrenoceptors in the cardiovascular system. Pharmacol Biochem Behav 1985; 22: 827-833, doi: 10.1016/00913057(85)90535-0.

27. Piascik MT, Perez DM. Alpha1-adrenergic receptors: new insights and directions. J Pharmacol Exp Ther 2001; 298: 403-410.

28. Pertovaara A. Noradrenergic pain modulation. Prog Neurobiol 2006; 80: 53-83, doi: 10.1016/j.pneurobio.2006. 08.001.

29. Grisanti LA, Woster AP, Dahlman J, Sauter ER, Combs CK, 
Porter JE. Alpha1-adrenergic receptors positively regulate Toll-like receptor cytokine production from human monocytes and macrophages. J Pharmacol Exp Ther 2011; 338: 648-657, doi: 10.1124/jpet.110.178012.

30. King EW, Audette K, Athman GA, Nguyen HO, Sluka KA, Fairbanks CA. Transcutaneous electrical nerve stimulation activates peripherally located alpha-2A adrenergic receptors. Pain 2005; 115: 364-373, doi: 10.1016/j.pain.2005.03.027.

31. Chen CC, Johnson MI, McDonough S, Cramp F. The effect of transcutaneous electrical nerve stimulation on local and distal cutaneous blood flow following a prolonged heat stimulus in healthy subjects. Clin Physiol Funct Imaging 2007; 27: 154-161, doi: 10.1111/j.1475-097X.2007.00731.x.

32. Lazarou L, Kitsios A, Lazarou I, Sikaras E, Trampas A. Effects of intensity of Transcutaneous Electrical Nerve
Stimulation (TENS) on pressure pain threshold and blood pressure in healthy humans: A randomized, double-blind, placebo-controlled trial. Clin J Pain 2009; 25: 773-780, doi: 10.1097/AJP.0b013e3181a7ece3.

33. Eichler HG, Ford GA, Blaschke TF, Swislocki A, Hoffman BB. Responsiveness of superficial hand veins to phenylephrine in essential hypertension. Alpha adrenergic blockade during prazosin therapy. J Clin Invest 1989; 83: 108112, doi: $10.1172 / \mathrm{JCl} 113845$.

34. Perez DM, Papay RS, Shi T. Alpha1-adrenergic receptor stimulates interleukin-6 expression and secretion through both mRNA stability and transcriptional regulation: involvement of p38 mitogen-activated protein kinase and nuclear factor-kappaB. Mol Pharmacol 2009; 76: 144-152, doi: 10.1124/mol.108.054320. 